University of Louisville

ThinkIR: The University of Louisville's Institutional Repository

Electronic Theses and Dissertations

$5-2012$

\title{
The KMEA and its string program : teaching techniques of string teachers.
}

Lyndsay Blair Joseph 1984-

University of Louisville

Follow this and additional works at: https://ir.library.louisville.edu/etd

\section{Recommended Citation}

Joseph, Lyndsay Blair 1984-, "The KMEA and its string program : teaching techniques of string teachers." (2012). Electronic Theses and Dissertations. Paper 715.

https://doi.org/10.18297/etd/715

This Master's Thesis is brought to you for free and open access by ThinkIR: The University of Louisville's Institutional Repository. It has been accepted for inclusion in Electronic Theses and Dissertations by an authorized administrator of ThinkIR: The University of Louisville's Institutional Repository. This title appears here courtesy of the author, who has retained all other copyrights. For more information, please contact thinkir@louisville.edu. 
THE KMEA AND ITS STRING PROGRAM:

TEACHING TECHNIQUES OF STRING TEACHERS

\author{
By \\ Lyndsay Blair Joseph \\ B.A., Murray State University
}

A Thesis

Submitted to the Faculty of the

College of Fine Arts of the University of Louisville

in Partial Fulfillment of the Requirements

for the Degree of

Master of Music Education

Department of Music Education

University of Louisville

Louisville, Kentucky

May 2012 
THE KMEA AND ITS STRING PROGRAM:

TEACHING TECHNIQUES OF STRING TEACHERS

By

Lyndsay Blair Joseph

B.A., Murray State University, 2007

A Thesis Approved on

May, 2012

by the following Thesis Committee:

Amy L. Acklin

Thesis Director

Robert Amchin

Kimcherie Lloyd 


\section{DEDICATION}

This thesis is dedicated to my parents

Mr. Dennis Joseph and Mrs. Ronecca Joseph who have

given me support, guidance and have been my lifetime Christian role models. 


\section{ACKNOWLEDGMENTS}

I would like to thank my professor Dr. Amy Acklin for her leadership and direction she has given me over the past two years. I would also like to thank the other committee members Dr. Robert Amchin and Ms. Kimcherie Lloyd for their comments and assistance. Also many thanks to all of my instructors and people in my life who have influenced me as a musician and educator: Nancy and Dr. John Steffa, Karen O'Daniel, Elaine Shurley, Dr. Fredrick Ripley, Dr. Sue Jean Park, and Alvin and Brittany MacWilliams. I would also like to express my gratitude to my other family members who have always been supportive, including my brother Austin Joseph, uncle Mitch Portis, grandparents Robert and Linda Portis, Wavil and Lola Joseph and my greatgrandmother Ernestine Staples and the late Hafford Staples. 


\author{
ABSTRACT \\ The KMEA and its String Program: \\ Teaching Techniques of String Teachers \\ L. Blair Joseph
}

May 2012

The purpose of this study was to identify the teaching techniques of current string teachers within the Kentucky Music Education Association. Participants $(N=31)$ completed a 17-question survey that focused on teaching techniques they use while teaching string orchestra. The participants included elementary, middle, and high school public string teachers in the Commonwealth of Kentucky. Results collected from the survey included demographic information about the teachers including the grade levels taught, number of years of teaching experience, the amount of time spent teaching per week, the participants primary instrument, and whether or not they gave private lessons. The survey questions also gathered information about specific teaching techniques including rehearsal warm-ups, tuning, open strings, scales, intonation exercises, dynamics, bow exercises, rhythms, shifting and chorales. Suggestions for further research are offered related to teaching techniques for string teachers. 


\section{TABLE OF CONTENTS}

PAGE

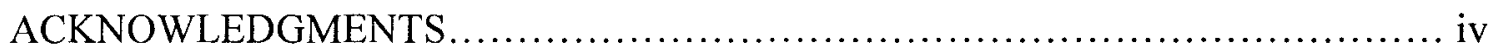

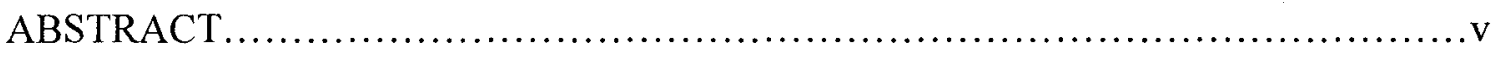

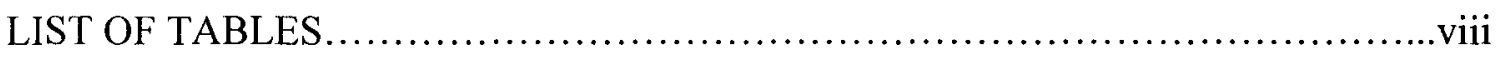

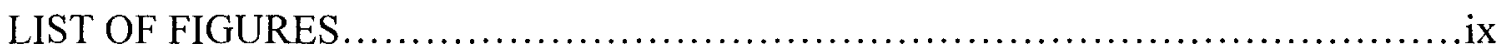

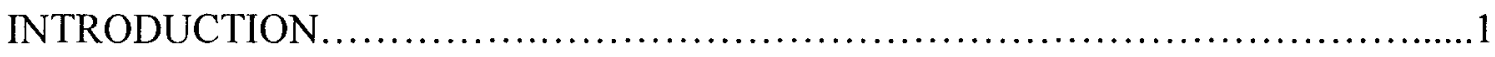

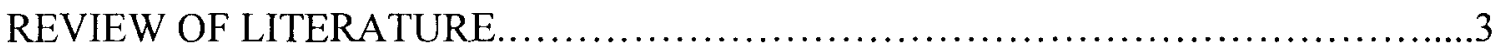

TEACHING BEHAVIORS.................................................

EFFECTIVE TEACHING ...........................................

MODELING.................................................... 6

INSTRUCTIONAL STRATEGIES................................. 8

STRING RESEARCH...................................................

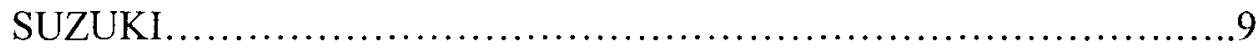

STRING TECHNIQUES .........................................11

Tone

Bowing..................................................11

Pitch.....................................................

Shifting................................................. 13

Vibrato......................................................... 14

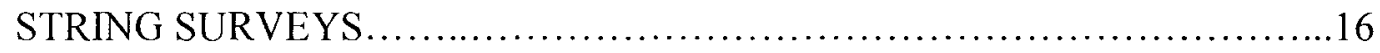

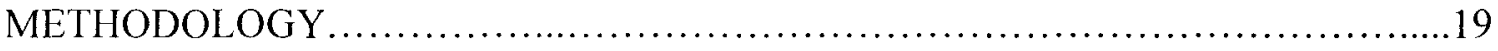




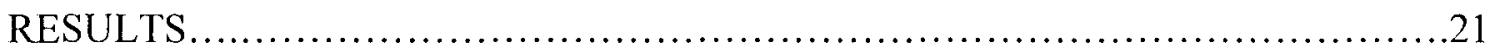

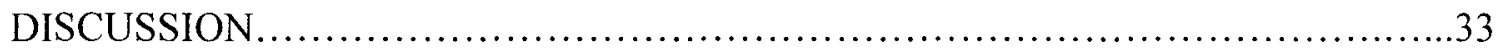

SUMMARY AND CONCLUSIONS ........................................... 38

Method Books.............................................................................. 38

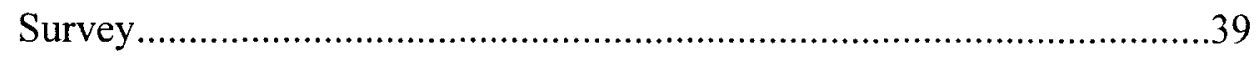

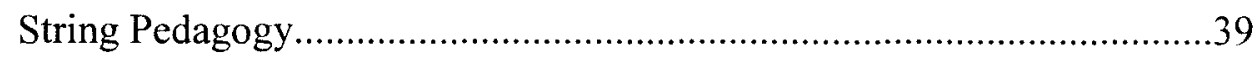

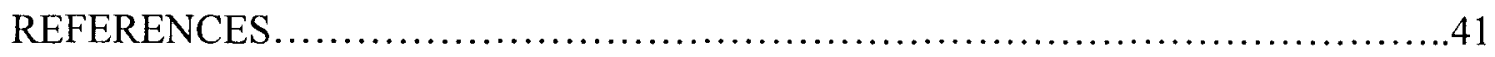

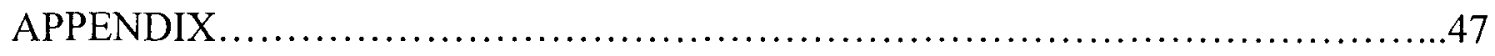

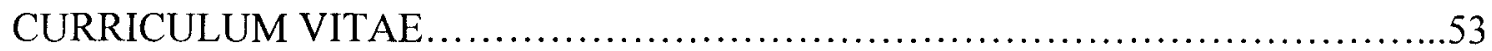




\section{LIST OF TABLES}

TABLE

PAGE

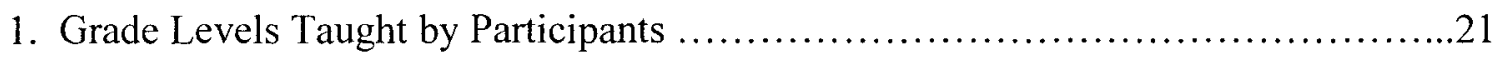

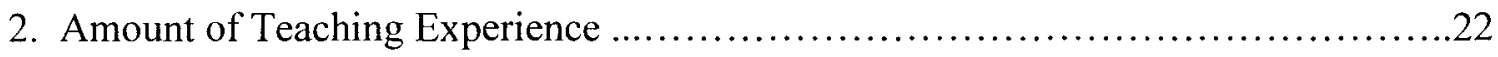

3. Sum of the Participants Total Weekly Time Spent Teaching $\ldots \ldots \ldots \ldots \ldots \ldots \ldots \ldots . \ldots 22$

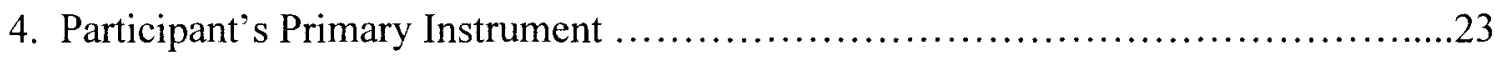

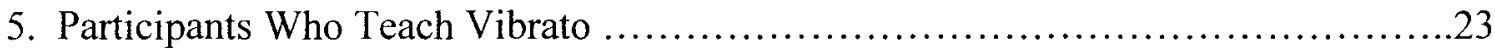

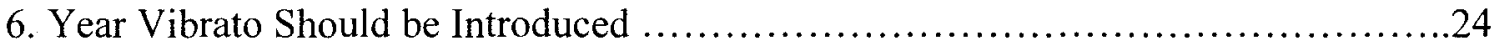

7. Participants Who Use a Method Book During Rehearsal ...........................26

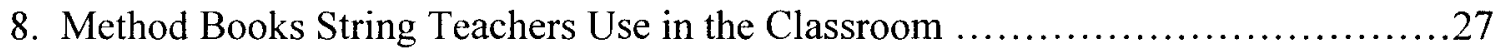

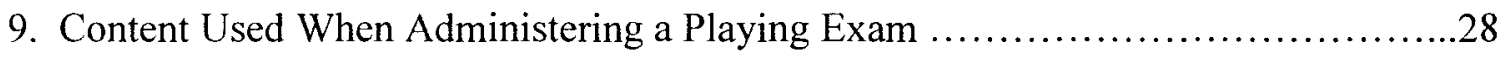

10. Activities Used for Orchestra Rehearsal Warm-Up ............................ 32 


\section{LIST OF FIGURES}

FIGURE

PAGE

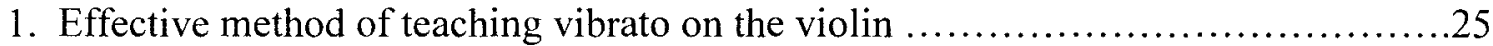

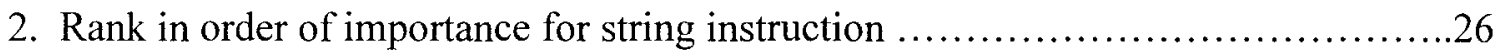

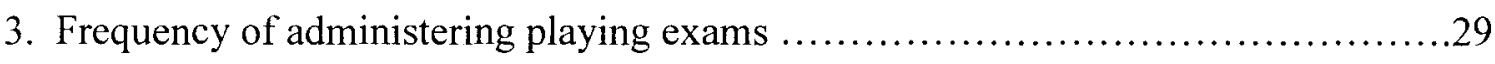

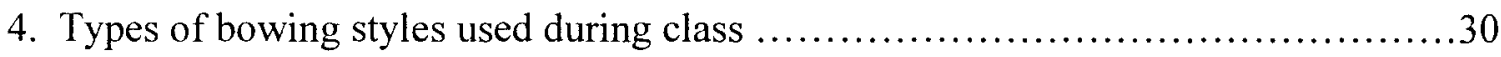

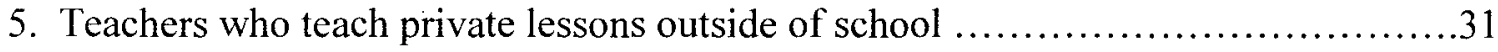

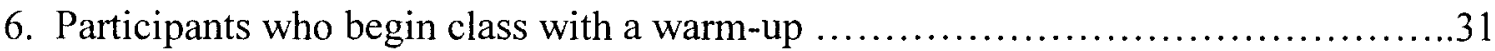




\section{INTRODUCTION}

The origin of the word "pedagogy" is derived from the Greek language that literally translates to "lead the child" (Pedagogy, n.d.) However, within modern society the term now refers more generally to the art of teaching. The teaching process is not easily defined and involves careful decisions about instruction and evaluation. As a teacher, finding ways to guide students in one's classroom can be challenging. Many educational approaches and resources are available to use, but how do teachers choose between the wealth of techniques and methods? Specifically, how do music teachers determine an instructional strategy to use in the classroom?

In 1994 the National Standards for Arts Education (Consortium, 1994) provided a guideline for dance, music, theatre and visual arts education. The Consortium developed a nine standard guideline for music teachers to follow. Although the National Standards provide a framework for music teachers, they do not provide a detailed music curriculum. Interestingly, this is not the case for other subjects such as math and science. Although the National Standards for Arts allows for flexibility in curriculum planning, it also leaves a void to create a unified plan of direction for music educators.

Music education can be taught using different approaches of techniques and methods. When defining standards for string education, one needs to consider various pedagogical elements. String education requires consideration for many mechanical and technical, aspects of musicianship. The absence of an established pedagogy to 
standardize approaches in string education presents difficulties for educators. There has been a recent movement in the American String Teachers Association (ASTA) which led to a curriculum for string educators to follow as a guideline for teaching in the classroom (Roberts, 2011). However, the application and effectiveness of this new methodology has not yet been documented.

The purpose of this study is to identify the teaching techniques, method books and other resources that string teachers use in the state of Kentucky. While adding a string curriculum through ASTA has made strides in string education, there is still a lack of research. String educators' have limited resources when examining effective uses of methods and techniques. This study hopes to provide insights in to the specific methods being used by string teachers in the state of Kentucky. 


\section{REVIEW OF LITERATURE}

The KMEA and its String Program:

Teaching Techniques of String Teachers

Educators strive to find the best methods, models and techniques to present to their students. The same is also true for string educators, who face the challenge of knowing what is most effective in the classroom when teaching a variety of string instruments to a diverse population of students. Although several string studies exist in which teachers can formulate a set of best practices, there is still a lack of research in the area of string education. The literature search did, however, reveal a vast amount of research in the field of music education. Many of the results from these studies can apply to string teachers. This review of literature is organized into three main categories: teaching behaviors, string research and string surveys.

\section{TEACHING BEHAVIORS}

\section{Effective Teaching}

Research suggests that using sequential patterns followed by an analysis on the specific task helps to complete the sequence set for class learning targets (Maclin, 1993). An example of a sequence pattern would be a teacher's presentation of a task, a student's response or interaction with the task or teacher, and immediate teacher feedback. Correct sequence patterns require that the task presentation include academic material and feedback related to the task (Arnold, 1995). Planned instructional strategies along with using corrective feedback can help the process of using sequential teaching methods. 
Price (1992) designed three experiments on the effects of instruction. These were separated into the categories of teaching practica, feedback from the course instructor, and videotaped self-observation on undergraduates' use of complete sequential patterns and sequential-pattern components. Madsen (2003) found that teachers who used an engaging delivery of instruction, such as sequential patterns, were rated higher than teachers with an un-engaging delivery. Interestingly, the more engaging teachers were rated higher even when giving inaccurate information.

Research suggests that there are many elements that factor into evaluating students and their growth. Yarbrough \& Madsen (1998) measured the categories of behaviors that may contribute to effective teaching. The ten categories of student and teacher behavior were: time use, musicianship, accuracy of presentation, student attentiveness, student performance quality, enthusiasm, intensity, pacing, personality, and overall effectiveness. One way to enhance teacher effectiveness is by evaluating their performance as music teachers (Bergee, 1992). Another aspect that is influential on teacher effectiveness is based on music instructors teaching styles and how it was modeled for them (Gumm, 1994). Eight aspects of teaching styles are Student Independence, Teacher Authority, Positive Learning Environment, Aesthetic Music Performance, Nonverbal Motivation, Time Efficiency, Group Dynamics, and Music Concept Learning. These styles allow teachers to create their own learning environment, and it reflects how the students perform in and out of the classroom.

In addition to teaching styles, it has been found that having experience as a music teacher can be beneficial when focusing the students' attention on learning activities. 
Occasionally, differences are displayed when examining preservice and experienced music teachers' ratings and comments on teacher effectiveness and student learning after observation (Madsen \& Cassidy, 2005). Researchers have found that teachers with experience in the class room do respond differently to evaluations. Experienced music teachers were more critical in their evaluations and made more judgment statements than the undergraduate subjects. They also spent less time giving directions (Wagner \& Strul, $1979 \&$ Witt, 1986).

Although experienced teachers may have more developed techniques, Hamann \& Baker (1996) discovered helpful practices for novice teachers when trying to gain classroom experience. The study listed early field experience teaching episodes, peerteaching episodes, episodes of subjects watching videotapes of their teaching, and episodes of subjects watching videotapes of their teaching with a coaching instructor as beneficial models. Certain practices, for example, lesson planning, contribute to effective music teaching when examining the relationship of teacher-defined traits (Hendel, 1995, Brittin, 2005).

Lastly, the use of recordings and advancements in technology can be helpful to music teachers in developing effective teaching behaviors. Video recordings allow teachers to critique themselves after teaching in the classroom. Results from a study by Stuart (1979) indicated that both error detection training and in-class conducting increased the trainees' recognition of both errors and appropriate string usage. 


\section{Modeling}

Research suggests that using various models, whether it is physical or verbal, helps a student's performance. For example, Colprit (2000) conducted an examination on teacher and student behavior in 48 violin and cello lessons taught by 12 expert Suzuki string teachers. All 15-minute, 30-minute and 60-minute lessons were videotaped. The researcher analyzed teacher-student interactions as string teachers attempted to accomplish positive change in student performance. The teacher identified an aspect of student performance that needed improvement. Teacher and student performance approximations were categorized by singing, chanting, claping, or dance. Verbalizations included: information statements, questions posed by the teacher and student responses, directives, approvals, and disapprovals and off-task statements. Results indicated that approximately $45 \%$ of the total class time was teacher verbalization, $20 \%$ teacher modeling and $41 \%$ student performance. Additional results indicated that it was important to have a positive relationship between the student and teacher during lessons.

Another researcher (Rosenthal, 1984) examined the relative effectiveness of four modeling conditions on instrumentalists' musical performance. Independent variables included a guided model, (a combined verbal and aural example of a complex musical selection), an aural model only, a verbal guide only, and a practice only model. College music education students $(N=44)$ were randomly assigned to one of the independent variables. Dependent variables were the instrumentalists' correct notes, rhythm, dynamics, tempo, and phrasing/articulation. Subjects in the "aural only" group showed significantly $(p<.05)$ higher scores from all other groups. Subjects in the "guided model" group scored significantly $(p<.05)$ higher than subjects in the guide only and practice 
only groups. Significant differences $(p<.05)$ were found among groups in the performance of notes, rhythms, dynamics, and tempo. No significant differences were observed among groups in phrasing/articulation. Research suggests that modeling may be an effective technique for students to try and replicate in the classroom. Modeling can also help students develop musical discrimination skills (Delzell, 1989).

There are a variety of ways to examine the effects of modeling, self-evaluation, and self-listening for junior high school instrumentalists' music performance and attitude about practice. Hewitt (2001) administered a pretest/posttest to woodwind, brass, and percussion students $(N=82)$ in the seventh $(n=36)$, eighth $(n=31)$, or ninth grade $(n=$ 15). Data showed that participants who listened to a model during self-evaluation improved more than those who did not listen to a model in the areas of tone, melodic accuracy, rhythmic accuracy, interpretation, and overall performance. There was no improvement in intonation, technique/articulation, or tempo. When self-evaluation was not used, the modeling groups were no different in any performance subarea. Additional results indicated that groups who listened to a model improved their performance more than the students who did not listen to a model in the areas of tone, technique/articulation, rhythmic accuracy, tempo, interpretation, and overall performance. No statistically significant $(\alpha=.05)$ findings for self-listening or practice attitude were identified.

Even though a student's view may be indifferent about their own performance, often a recorded musical model, in the context of an ensemble rehearsal, can be an effective way to improve student's performance. For example, over a 5-week treatment period, directors of three middle/junior high and two high school bands systematically included professional recordings as part of their preparation of selected pieces (Morrison 
et al., 2004). Students completed weekly self-evaluation reports assessing their individual progress and their ensembles' progress on model and no-model pieces. Using numerical and free-response formats, students evaluated self-achievement and ensemble achievement on notes/rhythms, articulation/dynamics, tuning, and balance. Evaluations revealed no significant difference $(p>.05)$ in achievement between model and no-model pieces on pretreatment and post-treatment performance recordings. High school students demonstrated more positive self-evaluations for their own individual playing rather than their ensembles' performance. Middle school/junior high students were significantly more positive toward the model pieces $(p<.01)$ than their own pieces. All students provided a greater number of free-response comments for model pieces. When listening to one's own piece, it seems that middle school students react more critically to their own performance than that of a model performance. This is something to keep in mind when allowing middle school students to analyze their work in the classroom. Creating a positive environment can be a beneficial way for students to be able to critic and improve their performance without feeling negative about what they have produced.

\section{Instructional Strategies}

Other factors that can affect a student's performance is how the teacher provides instructional guidance. Influential teachers have helped pave the way of the methods commonly used when teaching string positions and giving instruction. Gholson (1998) created two categories of strategies which included "preparatory" and "facilitative" when observing violin pedagogue Dorothy DeLay. She was observed in her studio and her teaching practices were documented through field notes, audiotapes, and contextual artifacts. Preparatory strategies were characterized by teacher actions that revealed the 
overall goals of instruction and processes for probing student frames of reference.

Facilitative strategies were characterized in terms of lesson-goal development, cognitive magnification of performance details, the use of metaphor, and the creation of contextual regions of comfort and challenge. At the end of the study the notes of DeLay were reviewed and two effective categories were found. She used "prepared activities" of instruction (which were to get acquainted with the students) by asking questions, and then "formed goals" that would guide the students through the lessons.

Lastly, Duke and Henniger (2002) explored the effects of positive or negative feedback from the teacher. The study evaluated methods of effective leadership and guidance during lessons. The results indicated that when making verbal corrections, it is good for teachers to use positive corrective feedback. Salzberg \& Salzberg, (1981) found that although students differed in response to the teaching styles, praise was always as effective as corrective feedback in changing the left-hand position for violin and it had a more lasting effectiveness.

\section{STRING RESEARCH}

\section{Suzuki}

Over the past 20 years, the Suzuki method has grown to be a part of many string communities. Studies have compared Suzuki methods with traditional and conservatory methods. The structure of the method, and the way it is taught, may impact how students behave in the classroom. For example, Scott (1992) conducted a study with 3 to 5 year old children $(N=80)$, who were enrolled in individual Suzuki violin lessons, individual and group Suzuki violin lessons, creative movement classes, preschool activities or 
classes, or who were not enrolled in any organized preschool activities or classes.

Results of classroom and lesson videotapes provided information on teacher and student behaviors. Attention and persistent behaviors were analyzed through observation of videotape recordings of subjects performing two tasks designed by the experimenter. Both Suzuki groups scored higher on all attention task variables than did children in the other groups. The subjects receiving both individual and group Suzuki violin instruction spent significantly $(p<.001)$ more time on the perseverance task than did all other subjects in the creative movement or preschool group.

In addition to increasing attention behaviors, research has suggested that the Suzuki method could possibly help a student be persistent on certain musical tasks and that the age of a student might affect their ability to perform musical tasks, such as rhythm (Nelson, 1984). Nelson developed a task to measure the rhythmic conservation in young instrumentalists, and to determine the validity of the task. Twenty Suzuki violin students between 4 and 8 years old were given an author-designed rhythmic task and a series of standardized tasks that measured area and length conservation. The training level of the students was found to be less of a factor in their ability to conserve rhythm than was age and area-length conservation. Results indicated that the conservation of rhythm task was positively related to success on the conservation of area and length tasks. It appears that Suzuki may have a positive impact on the use of activities and the amount of time spent on rhythmic tasks with students.

There are a variety of methods and techniques to use for string educators. One particularly prominent approach is the Suzuki method, which promotes group and private lessons through the "String Project." Byo \& Cassidy (2005) wanted to encourage string 
education majors to become string teachers and to inspire the growth of new school orchestra programs to study string instruments at low costs. Survey data was collected by using a survey and project directors were interviewed by phone. Results indicated that the majority of student teachers were music education majors who received professional and financial benefit from participation, and who were engaged in authentic string teaching in productive and rewarding settings. The String Project seemed to have filled a void where school string programs did not exist, and functioned to supplement strings instruction available in the schools.

\section{String Techniques}

Tone. Research has suggested that performance achievement in strings can be linked to good standard technique and tonal intonation. String teachers use different approaches with their students to achieve better performances. One approach is to develop a satisfying musical experience from the start (Rolland, 1947). Other techniques include developing tonal beauty, reading music well and keeping eyes on the instrument. These teaching aspects may have a different impact on a student's performance based on the student's abilities, opportunities and musical environment.

Bowing. String students come into a music program with different backgrounds of musical performance, experience and aptitude. The methods they were taught will initially influence their performance on an instrument, such as the different approaches that a teacher might use to teach a specific bow stroke or the technique, and how they would demonstrate this to the student. The relationship between the diagnostic skills of string teachers and the performance competencies of their students in simple detaché 
violin bowing was identified in a study by Gillespie (1991). Twenty-two string teachers took a violin-bowing diagnostic skills test. Three students were randomly selected and their violin bowing skills were rated. Data revealed no significant correlation between the diagnostic test scores of the teachers and the performance ratings of their students. Additionally, the teachers rated the influence of 22 different factors on the development of the performance competencies of their students and again, no significant correlations $(p>.05)$ were found. Research suggests that teachers can rate and identify performance abilities on violin bowings just as well as a diagnostic test.

Pitch. In addition to individual bowing performance, students in an orchestra also need to develop ensemble skills and intonation. One element for string ensembles is to center on pitch accuracy as a goal for performance. Smith (1995) measured the effects of a pitch-matching training program on string students' aural pitch discrimination. The training program developed in the study consisted of a set of audio pitch-matching tapes that were specifically designed for use with the TAP Pitch Master Machine. Participants $(N=96)$ were sixth grade string students that were randomly assigned to either one of four groups that trained with the Pitch Master Machine or one of four groups that performed the same exercises in class. A panel of three public school string teachers served as judges and rated each subject's performance pitch accuracy on a Likert-type scale. The results indicated that the subjects who worked with the Pitch Master Machine made statistically significant $(p=.001)$ gains on pitch discrimination, which appeared to have a positive effect on performance pitch accuracy.

The ability to improve pitch accuracy and produce a good tone with beginning string players can also be improved if a teacher aids the student with finger markers for 
their instrument. For example, Beronzi (1997) randomly assigned harmonic training to beginning string students. The Test of Beginning String Performance was used as a posttest to evaluate students' performance skills. The materials students played included a one-octave D major scale and arpeggio, Twinkle, Boil them Cabbage Down, Row Row Your Boat, and Ode to Joy. Each student received 90-minutes of weekly instruction to improve music performance skills. The students without markers had transparent tape and the instructors personally took time to explain the shape of the hand and where the fingers should be placed. In conclusion, there were no significant differences $(p>.05)$ across schools between intact classes assigned to harmonic conditions. Even though it seems that transparent tape is just as effective, just not as visible, both are still a guide for the students to use when placing their fingers on the fingerboard.

Shifting. Finger markers on the instrument can also be helpful when a student is learning different positions on the fingerboard of their instrument. For example, a visual marker can help guide the student's finger and ear to where the correction position is located. While starting in first position can be traced as early as the $17^{\text {th }}$ century (Cowden, 1972), not all agree that starting in first position is best. Some argue in favor of beginning instruction in third position because 1) the half steps and whole steps lie closer together, 2) the fourth finger is used immediately, and 3) the body of the violin serves as a reminder when the heel of the left hand is getting out of position. Cowden also discusses the disadvantages of beginning in third position, which includes a reduced string length that makes tone production more difficult. Other issues of starting in third position are the combination of open strings and stopped notes, which would be difficult to use. The left hand may develop stiffness because the student is likely to support the 
downward pressure with their wrist instead of their thumb, and there are few materials available for teaching this approach.

To further investigate this, Cowden began with a control group $(n=18)$ and experimental group $(n=19)$. The student participants practiced their violin thirty minutes daily for six days per week. Students played one piece in first position, one piece in third position and one piece involving shifting between the two positions. The judges' ratings indicated no significant difference $(p>.05)$ in the performance of shifts between first and third positions between the control group and the experimental group for intonation and rhythmic accuracy.

Vibrato. In addition to learning how to technically shift, a student must also learn the use of vibrato, which can subtly waiver the pitch. Research suggests that when a student performs vibrato, that visual indications can influence the teacher's ratings of performance evaluation. For example, Gillespie (1997) examined sight influences on the sound of the vibrato. Gillespie compared the vibrato ratings of inexperienced and experienced violinists and violists. Inexperienced players $(N=33)$ and experienced players $(N=28)$ were videotaped while performing vibrato. A board of experts rated the vibrato under two conditions: audio only and videotape. They examined width, speed, evenness, pitch stability, and overall sound. The experienced players' vibrato was rated higher for all factors, regardless of the mode of presentation. In addition, results revealed significantly ( $p=.04)$ higher audiovisual ratings for pitch stability, evenness, and overall sound for the inexperienced players, and for pitch stability in the experienced players. 
Additional research on vibrato has examined the vibrato rates and widths between university and high school violin and viola players. MacLeod (2008) used Dvorak's Symphony No. 9 as the musical stimuli and investigated the influence of pitch register on the vibrato rate and width for violin and viola. Analysis showed that pitch register significantly affected $(p<.01)$ the vibrato rates and widths of the performers. Musicians vibrated $0.32 \mathrm{~Hz}$ faster and approximately 26 cents wider during high pitches than during low pitches. Dynamic level also affected vibrato width. Performers increased vibrato width approximately 4 cents in the forte passages when compared to the piano passages. Also, violinists demonstrated a tendency to vibrate slightly faster and wider than violists, and university performers varied their vibrato width to a larger extent between the piano and forte passages than did the high school performers.

Other research on vibrato has been conducted by Geringer \& Allen (2004) who investigated vibrato performance in university student and high school string players $(N=40)$. The violinists and cellists performed an eight-measure passage both with and without vibrato. Analyses showed that the mean rate of vibrato was approximately 5.5 $\mathrm{Hz}$, with no significant differences between instruments or the performer experience level. The mean width of violin vibratos was larger than the cello vibratos. Violinists' mean pitch levels were sharper than the cellists' in both vibrato and nonvibrato performances. Analysis of intonation patterns within the duration of tones showed that performers were more stable when using vibrato. University players were more likely to become sharper during both vibrated and non-vibrated tones compared to the younger players. Pitch fluctuation during vibrato included alternations both above and below the pitch, rather than fluctuating only above or only below the conceived pitch. 
Whether playing in tune or focusing on vibrato, the movement of the hands controlling the bow and fingers on a string fingerboard plays an integral part to the sound being produced. Jacobs (1969) examined trained and untrained string pupils ranging from ages 11-13(N=10). The subjects trained aurally for half an hour over a period of 20 days on their instruments. Intonation errors that the study identified were divided into movements by the fingers and tones. The areas evaluated were 1) tones played in tune with correct movements and position of the left fingers, 2) tones played too high or low, 3) playing in tune with wrong movements and positions of the left fingers and 4) playing in tune with right movements of the left fingers. The results revealed that the group with trained musical hearing made significantly $(p<.001)$ more errors with the movements and positions of their left fingers than the group with untrained musical hearing.

\section{String Surveys}

How music instruction is implemented can vary among schools and teachers. Many factors can influence whether or not string education is offered in a public school in the United States, including a school district's location, size, and socioeconomic level. Smith (1997) collected data reports from state departments of education (18), reports from state music education associations (6), and mail-outs and phone calls to individual districts (26). A total of 2,268 districts were identified that offered string instruction. Within these districts there were elementary $71.42 \%$, middle $78.52 \%$, and high school $80.15 \%$ string instruction offered. Additional results revealed that the majority of string instruction occurred in average socioeconomic-sized urban districts located in the Eastern North Central and Northwest part of the United States. 
Another survey was conducted to investigate public school music curricula comparing music, choral, band, and string programs within Indiana (Schmidt et al. 2006). The program characteristics were examined in relation to the school demographic characteristics of enrollment, percentage of minority students, and percentage of students receiving free lunch. Indiana public school districts $(N=98)$ were randomly selected. Response rate by school corporation was $100 \%$ and final response rate for the total sample of music teachers was $63.1 \%(N=391)$. Teachers provided information gathered through a survey concerning 1) music curricular offerings by area and grade level; 2) teaching load and instructional contact time; and, 3) class enrollments and performance activities. For each school district sampled, data was obtained from the State Department of Education and the Indiana State School Music Association. Results indicated wide variability between program characteristics, enrollment, participation rate, and performance activity. Approximately $64 \%$ of the sample indicated that general music was at least part of their teaching load. Teaching load was significantly correlated $(r=-$ .61) with time allocations for five of seven instructional activities in general music. Median student participation rates in music at the secondary level varied from $6 \%$ (strings) to $17 \%$ (band) to $24 \%$ (choral). String programs represented approximately $16 \%$ of the sample school corporations and those that offered strings had larger school enrollments than those not offering strings. However, it is often a challenge for string teachers and public school orchestras to find financial support within school system and communities.

Even though string ensembles are offered in different areas of the country and at different levels, Hartley \& Porter's (2009) research supports the notion that most string 
ensembles start during the fourth grade. The developments in string enrollment were accessed focusing on the students and their retention at a particular starting grade level. A statewide survey of school string programs was given with the intent that results could be widespread across a large spectrum of areas and regions. The survey was sent to 556 elementary, middle and junior high school orchestra teachers. Results from a Chi-square test revealed no statistically significant difference $(p<.07)$ among the percentages of eligible students who enrolled and the grade levels of beginning string instruction. Retention results showed a higher retention rate for both variables with later start grades.

Another string survey focused on the grading practice of string education and examined the content of string instruction in the classrooms Gilliland, 2001). Gilliland launched the survey to determine the grading practice among the orchestra directors $(N)=48$ string teachers in the three districts in El Paso County. The questionnaire was formed to determine how different or alike the grading practice was among the teachers. The questions asked were about the time of day orchestra was held, how grades were given, and what subjects were covered. The results indicated that there was some diversity in the grading practices, but mostly similarities. An example of the similarities was the content the orchestra directors used when grading their students. Although a nation-wide and other state surveys have been conducted, there are no known studies in the state of Kentucky. Hopefully these results will help support the educational string program. 


\section{METHODOLOGY}

\section{Participants}

The participants $(N=31)$ selected for the study were certified public school orchestra teachers registered through Kentucky Music Education Association (KMEA). The participants resided or taught in the state of Kentucky. The participants were located through a membership of KMEA. KMEA has a website (kmea.org) which allows members to access listings of string educator members. As a resource for string teachers, they have a list of KMEA members email addresses as a reference of contact for educators who teach music in the state of Kentucky. There is an option on the website to select specifically only string educators for the purpose of the survey. After sending out 84 emails to the participants, 34 participants started the survey and 31 participants actually finished the survey.

\section{Materials}

The study was designed on a computer program called "Qualtrics" and was sent out through e-mail to the participants. The website used to design the survey, qualtrics.com, was obtained through the School of Business for University of Louisville students. When designing the survey there were many different websites to choose from, however, Qualtrics was chosen because of the easy to use layout design of the survey 
program and the unlimited questions one could ask when creating the current string pedagogy survey.

Survey Design

A trial survey was administered in the spring of 2011 using a variety of string players and university students. The trial revealed several questions that needed to be clarified. Some questions also changed as I was teaching in the public school system.

The design of the survey included 18 questions: 8 "fill in the blank" items, 4 "yes or no" questions, 5 "check the answers" and 1 "rank-in-order" question. The participants had an open amount of time to complete the survey and could return to the survey if they had started it and not finished. The survey was sent out the first time with a two week window for the participants to reply. A reminder email was sent out the second week and then a week later a personal email was sent out to all participants who had not yet responded to the previous emails. After the participants submitted the survey, I was notified through Qualtrics that the survey had been either started or completed. The survey results were sent back through email provided by the Qualtrics website. During the second week, after the survey had been launched, there was a KMEA conference in which hard copies of the survey were made into handouts to distribute to string teachers who had not yet participated in the study. This gained four more participants to include with the final results. After receiving all of the information, each individual question was analyzed. Some questions were analyzed in categories and others by the percentage of responses. 


\section{RESULTS}

This survey was taken by public string teachers registered through KMEA $(N=31)$. The survey results collected from the participants included demographic information about the teachers including the grade levels taught, number of years of teaching experience, the amount of time spent teaching per week, the participants primary instrument, and private lessons. Questions were also asked about teaching techniques, including, shifting, bowings used during class, vibrato and administering playing exams.

The results of the survey are as follows: Question one asked the participants for their consent to participate in the study. All thirty five participants answered "yes" when asked for consent to use their survey responses. Question two asked what grade levels and classes the participants taught (Table 1). From the fourteen responses, $36 \%$ taught at both Middle and High School, 36\% also taught at both Elementary and High School, 14\% taught at Elementary, Middle and High School, and 14\% taught only High School.

Table 1

Grade Levels Taught by Participants

\begin{tabular}{ll}
\hline Grade Level & $\begin{array}{l}\text { Number of } \\
\text { Respondents } \\
(N=14)\end{array}$ \\
\hline High School & 2 \\
Middle and High School & 5 \\
Elementary and High School & 5 \\
Elementary, Middle and High Sch & 2 \\
\hline
\end{tabular}


Question three asked how many years of teaching experience the participants had in teaching a school string program (Table 2). From the twenty eight responses, $32 \%$ had been teaching for one to five years, $29 \%$ between six to ten years, $25 \%$ from eleven to fifteen years, $7 \%$ for sixteen to twenty years, and $7 \%$ had taught between twenty one and twenty five years.

Table 2

Amount of Teaching Experience

\begin{tabular}{ll}
\hline Teaching experience in years & $\begin{array}{l}\text { Number of } \\
\text { Respondents } \\
(\boldsymbol{N}=\mathbf{2 8})\end{array}$ \\
\hline $1-5$ & 9 \\
$6-10$ & 8 \\
$11-15$ & 7 \\
$16-20$ & 2 \\
$21-25$ & 2 \\
\hline
\end{tabular}

Question four asked about the amount of time the participants taught orchestra every week (Table 3). The total combined results indicated that more hours were spent teaching high school students (169 hours) per week, followed by middle school (137 hours and 15 minutes), then elementary ( 35 hours and 50 minutes).

Table 3

Sum of the Participants Total Weekly Time Spent Teaching

\begin{tabular}{lll}
\hline $\begin{array}{l}\text { Elementary School } \\
(N=\mathbf{1 7})\end{array}$ & $\begin{array}{l}\text { Middle School } \\
(\boldsymbol{N = 1 8})\end{array}$ & $\begin{array}{l}\text { High School } \\
(N=\mathbf{2 6})\end{array}$ \\
\hline 35 hours 50 minutes & 137 hours 15 minutes & 169 hours \\
\hline
\end{tabular}


Question five asked about the participants' primary instrument (Table 4). The violin was the most frequent response, as thirteen participants' listed it as their primary instrument. The viola was next in responses with eight participants listing it as their main instrument. The cello had two responses and the double bass had three responses. Only one participant identified the piano as their primary instrument and the remaining individual responses were for a variety of non-string instruments.

Table 4

Participant's Primary Instrument $(N=14)$

\begin{tabular}{lc}
\hline Primary Instrument & $\begin{array}{l}\text { Number of } \\
\text { Respondents }\end{array}$ \\
\hline Violin & 13 \\
Viola & 8 \\
Cello & 2 \\
Double Bass & 3 \\
Piano & 1 \\
Euphonium & 1 \\
Clarinet & 2 \\
French Horn & 1 \\
Trombone & 1 \\
Trumpet & 1 \\
\hline
\end{tabular}

Question six asked if the participants taught vibrato (Table 5). The responses indicated that 29 of the 31 participants, or $94 \%$, teach vibrato to their students.

Table 5

Participants Who Teach Vibrato (N=31)

\begin{tabular}{lc}
\hline Answer & Percentage \\
\hline Yes & $94 \%$ \\
No & $6 \%$ \\
\hline Total & $\mathbf{1 0 0 \%}$ \\
\hline
\end{tabular}


Question seven asked at what stage vibrato should be introduced to students (Table 6). From the thirty one responses, $16 \%$ indicated the first year, $16 \%$ said the second year, $26 \%$ responded the third year, $26 \%$ replied the fourth year, and $16 \%$ suggested some other time period.

Table 6

Year Vibrato should be Introduced $(N=31)$

\begin{tabular}{lc}
\hline Year vibrato is introduced to student & $\begin{array}{l}\text { Number of } \\
\text { Respondents } \\
(\boldsymbol{N = 3 1 )}\end{array}$ \\
\hline $1^{\text {st }}$ Year & 5 \\
$2^{\text {nd }}$ Year & 5 \\
$3^{\text {rd }}$ Year & 8 \\
$4^{\text {th }}$ Year & 8 \\
$5^{\text {th }}$ Year & 0 \\
Other & 5 \\
\hline
\end{tabular}

Question eight asked the respondents what is the most effective method teaching vibrato on the violin (Figure 1). From the thirty one responses, 35\% replied arm vibrato, $29 \%$ responded wrist vibrato, $10 \%$ indicated finger vibrato, and $26 \%$ suggested another method of teaching vibrato. 


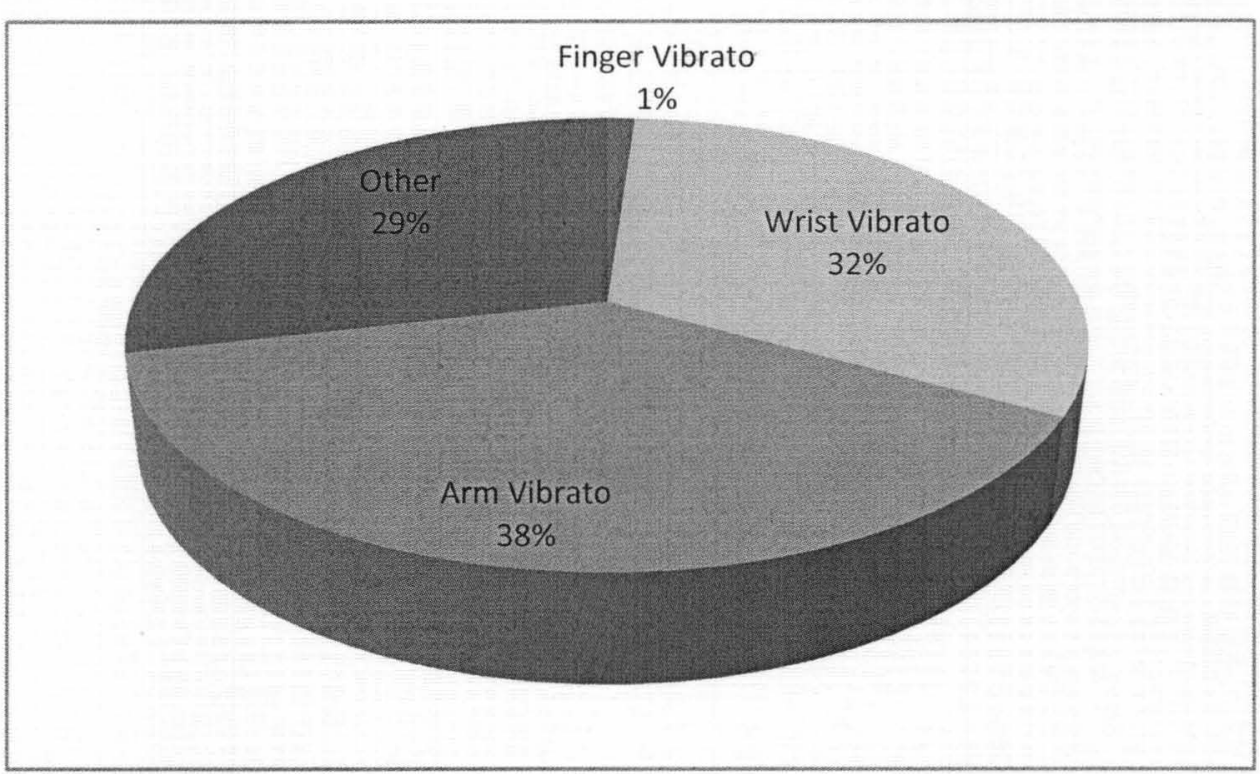

Figure 1. Effective method of teaching vibrato on the violin $(N=31)$.

Question nine asked the participants to rank in order from 1-4, with 1 being most important and 4 being least important, for how they prioritize classroom string instruction (Figure 2). For Techniques and Articulation, 11 participants ranked it number 1 for most important, 4 for $2^{\text {nd }}$ in importance, 14 , for third in importance and 1 for $4^{\text {th }}$ least important. For Phrasing, 0 participants raked it 1 for most important, 3 for $2^{\text {nd }}$ in importance, 3 for $3^{\text {rd }}$ in importance and 24 for $4^{\text {th }}$ least important. For Rhythm, 7 participants ranked it 1 for most important, 14 ranked it $2^{\text {nd }}, 8$ ranked it $3^{\text {rd }}$ and 1 ranked it $4^{\text {th }}$ for least important. For the Intonation, category 12 participants ranked it $1^{\text {st }}$ for most important, 9 ranked it $2^{\text {nd }}, 5$ ranked it $3^{\text {rd }}$ in importance and 4 ranked it $4^{\text {th }}$ for least important. 


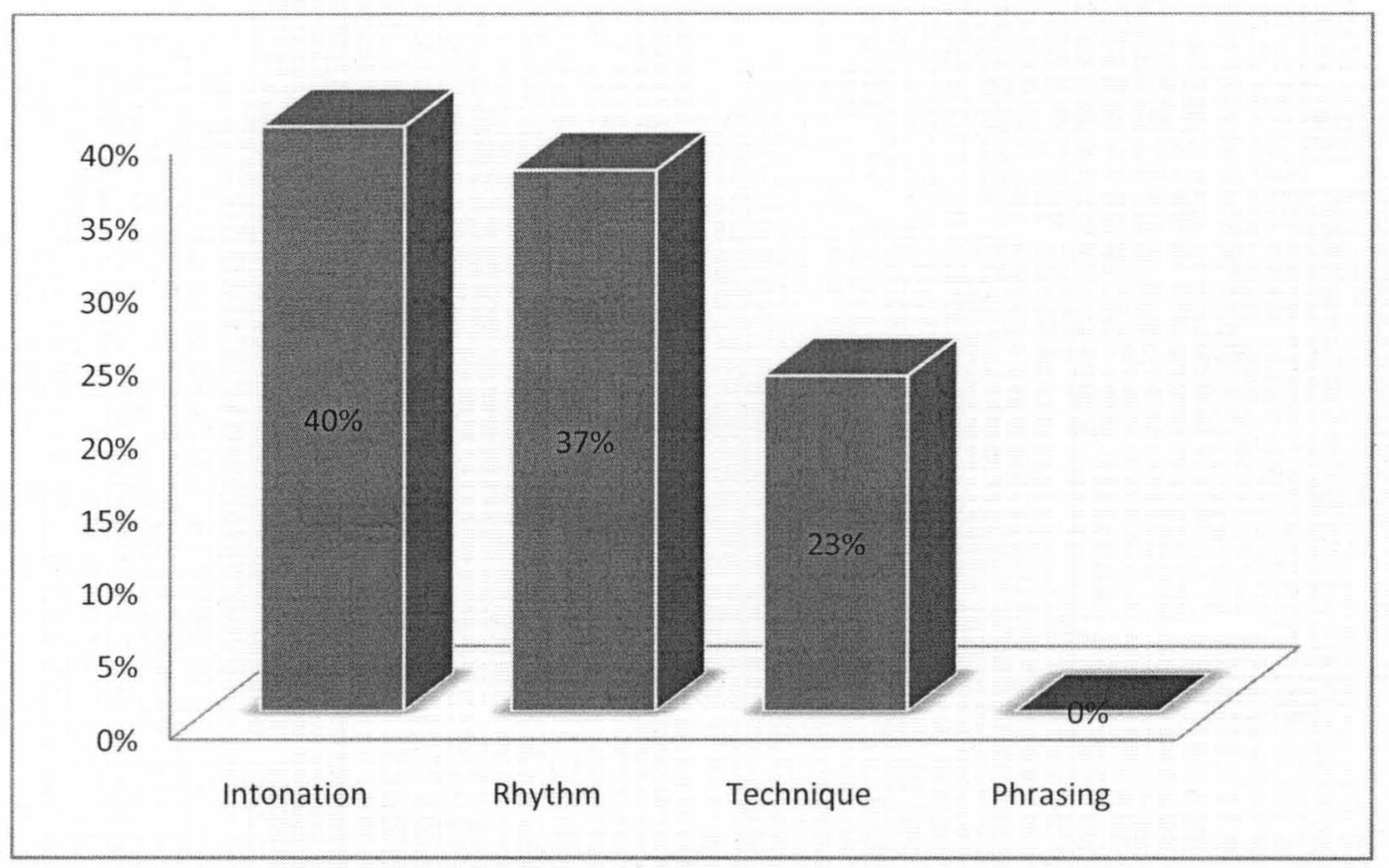

Figure 2. Rank in order of importance for string instruction.

Question ten asked if the participants use a method book during their rehearsals.

The responses indicated that 29 of the 31 participants, or $94 \%$, do use a method book during rehearsal.

Table 7

Participants Who Use a Method Book During Rehearsal $(N=31)$

\begin{tabular}{lc}
\hline Answer & Percentage \\
\hline Yes & $94 \%$ \\
No & $6 \%$ \\
\hline Total & $\mathbf{1 0 0} \%$ \\
\hline
\end{tabular}


Question eleven asked what kind of method books were used during teaching. Essential Elements was the predominant method book used by participants. A complete list of method books is given in Table 8 .

Table 8

Method Books String Teachers Use in the Classroom

Method Book

Superior String in 16 Weeks

Sevcik

Muller-Rusch

High Technique

Fine Tuning

How to Make your Band into Monster Sight Readers

String Explorer

\section{Percentage \\ of \\ Respondents}

$86 \%$
$7 \%$
$7 \%$
$7 \%$
$7 \%$
$7 \%$
$7 \%$
$14 \%$

Question twelve asked for the participants to check the type of content they test when administering a playing exam (Table 9). Results indicated that most participants focus on a combination of techniques. Rhythm and notes ranked the highest in priority and were checked $100 \%$ of the time on playing exams. Posture and bowings followed in importance with a $93 \%$ response rate. The other content that was checked frequently was articulation (83\%), bowings (83\%), dynamics (80\%) and phrasing $(45 \%)$. 
Table 9

Content Used When Administering a Playing Exam

\begin{tabular}{lll}
\hline Content & $\begin{array}{l}\text { Number of } \\
\text { Responses }\end{array}$ & $\begin{array}{l}\text { Percentage of } \\
\text { Responses }\end{array}$ \\
\hline Rhythm & & \\
Notes & 31 & $100 \%$ \\
Phrasing & 31 & $100 \%$ \\
Bowings & 14 & $45 \%$ \\
Posture & 29 & $93 \%$ \\
Articulation & 29 & $93 \%$ \\
Tone & 26 & $83 \%$ \\
Dynamics & 28 & $90 \%$ \\
\hline
\end{tabular}

Question thirteen asked how often playing exams are administered (Figure 3).

The most frequent response with both at $36 \%$ was $2-3$ times a month and once a month.

Fourteen percent of the participants gave playing exams less than once a month. The other responses were 2-3 times a week and once a week with 7\% response rate. 


\begin{tabular}{|c|c|c|}
\hline Answer & $\begin{array}{l}\text { Number of } \\
\text { Responses }\end{array}$ & $\begin{array}{c}\text { Percentage } \\
\text { of } \\
\text { Responses }\end{array}$ \\
\hline $\begin{array}{l}\text { 2-3 Times a } \\
\text { Month }\end{array}$ & 5 & $36 \%$ \\
\hline $\begin{array}{l}\text { 2-3 Times a } \\
\text { Week }\end{array}$ & 1 & $7 \%$ \\
\hline Daily & 0 & $0 \%$ \\
\hline $\begin{array}{l}\text { Less than } \\
\text { Once a } \\
\text { Month }\end{array}$ & 2 & $14 \%$ \\
\hline Never & 0 & $0 \%$ \\
\hline $\begin{array}{l}\text { Once a } \\
\text { Month }\end{array}$ & 5 & $36 \%$ \\
\hline $\begin{array}{l}\text { Once a } \\
\text { Week }\end{array}$ & 1 & $7 \%$ \\
\hline Total & 14 & $100 \%$ \\
\hline
\end{tabular}

Figure 3. Frequency of administering playing exams $(N=31)$.

Question fourteen asked what bowings the participants use during class (Figure 4). Détaché bowing is used in the classroom by $100 \%$ of the participants. Followed by 86\% respondents teach Martelé and Spiccato bowings to their students. "Other" was listed at $71 \%$ which means the participants use different kinds of bowings in their teaching. Collé (29\%) and Sautillé (21\%) are more advanced bow strokes and are use less often in the classroom. 


\begin{tabular}{|l|c|c|c|}
\hline Bowing & $\begin{array}{c}\text { Number of } \\
\text { Responses }\end{array}$ & $\begin{array}{c}\text { Percentage } \\
\text { of } \\
\text { Responses }\end{array}$ \\
\hline Détaché & 14 & $100 \%$ \\
Martelé & 12 & $86 \%$ \\
Collé & 4 & 4 & $29 \%$ \\
Sautillé & & 12 & $21 \%$ \\
Spiccato & 10 & $86 \%$ \\
Other & & $11 \%$ \\
\hline
\end{tabular}

Figure 4. Types of bowing styles used during class $(N=31)$.

Question fifteen asked for any technique or idea that was taught to them by a former teacher. The results for this question were typed out by the participants. One participant listed Paul Rolland "Action in String Playing" as a reference for technique. Another participant suggested when starting a new piece, to listen to a recording of it, clap it in parts to see how the rhythm fits together, review the scale of the key that it is in, and then play through the piece. In regards to technique, a participant suggested to use a mechanical approach for bowing, "set-up", posture, vibrato, and shifting. For cello vibrato, a participant suggested to practice on the collar bone. One participant commented on using a cognitive theory based approach to practice and to use rehearsal methods as well as "mental practice.". Lastly, a participant discussed singing solfege to help teach phrasing $\&$ intonation in a string orchestra. 
Question sixteen inquired if the participants also teach private lessons outside of the school system (Figure 5). The percentage of participants who teach lessons outside of the school system was $71 \%$.

\begin{tabular}{|l|c|c|c|}
\hline Answer & & Response & $\%$ \\
\hline Yes & & 10 & $71 \%$ \\
No & 4 & $29 \%$ \\
\hline Total & & 14 & $100 \%$ \\
\hline
\end{tabular}

Figure 5. Teachers who teach private lessons outside of school $(N=14)$.

Question seventeen asked if the participants begin their class with a warm-up.

The response rate "yes" was 100\% from the participants that begin class with some type of warm-up.

\begin{tabular}{|l|c|c|c|}
\hline Answer & Response & $\%$ \\
\hline Yes & 14 & $100 \%$ \\
No & 0 & $0 \%$ \\
\hline Total & 14 & $100 \%$ \\
\hline
\end{tabular}

Figure 6. Participants who begin class with a warm-up $(N=14)$.

Question eighteen asked participants who answered "yes" to question seventeen to describe the type of warm-up they use during their rehearsal. The result for this question was typed out in sentences by the participants. 
Table 10

Activities Used for Orchestra Rehearsal Warm-Up

\begin{tabular}{lc}
\hline Activities used in Warm-up & Percentage \\
\hline & \\
Stretching & $7 \%$ \\
Tuning & $29 \%$ \\
Open Strings & $7 \%$ \\
Scales & $93 \%$ \\
Intonation & $21 \%$ \\
Dynamics & $14 \%$ \\
Bow Exercises & $43 \%$ \\
Rhythms & $29 \%$ \\
Shifting & $7 \%$ \\
Chorales & $7 \%$ \\
\hline
\end{tabular}




\section{DISCUSSION}

The purpose of this study was to identify the teaching techniques of current string teachers who are members of the Kentucky Music Education Association. The results collected from the survey included demographic information about the teachers including the grade levels taught, number of years of teaching experience, the amount of time spent teaching in a classroom per week, the participants primary instrument, and whether or not they teach private lessons. The survey also gathered data regarding the method books teachers currently use in their classrooms.

The first demographic question, question number two, was asked to find out the grade level that the participants were currently teaching. Five of the participants taught middle and high school, five of the participants taught elementary and high school, two taught high school and two taught elementary middle and high school. Interestingly, and perhaps unlike other grade or subject areas, the majority of orchestra teachers in the survey taught more than one grade level.

The next demographic question, question 3, asked for the number of years the participant had taught. Results indicated that the majority of teachers fell into the 1-5 year category of teaching experience followed by 6-10 years, then 11-15, and the least amount of participants had 16-20 and 21-25 years of teaching experience. The findings

reflect that there are more new teachers than veteran teachers. These statistics show that the majority of the participants with the least amount of experience teaching gave 
feedback to the survey. Ideally it would have been preferred to have a more balanced representation of veteran and younger teachers.

When surveying the participants in question four about the amount of time per week they taught orchestra, results indicated that teachers spent more hours teaching high school orchestra than any other grade level. Within the district, collectively, there is a total of 168 hours of string instruction given at the high school level, which averages to 4.2 hours per week. The composite hours taught per week to elementary students were roughly 36 hours, which averages to 90 minutes per week of instruction. Middle school orchestra was taught for a total of 137 hours, which averages to 3.4 hours per week of string instruction. Music instructors often emphasis the importance of children having music in the classroom at a young age, yet the results of this study reflect an opposite trend.

Having experience on a string instrument can be useful when teaching string techniques to an orchestra. Question five asked the participants to list their primary instrument. Thirteen participants listed violin as their main instrument followed by eight violas, three double basses and two cellos. Interestingly, there were a vast number of string teachers whose primary instrument did not fall into the "string" category.

Question six focused on one technique that is common for string teachers to introduce to students, which is vibrato. When asked if they taught vibrato to their students, twenty-nine out of thirty one participants said "yes." The following question then asked at what stage vibrato should be introduced to a student. The majority of the participants thought that vibrato should be introduced between the fourth and fifth year of 
playing. Five of the participants responded with "other" to indicate that vibrato should be introduced either after a longer period of time or possibly when the student is ready.

There are different types of vibrato that a teacher could introduce to their students. Question eight asked which type of vibrato the participant thought was most effective when teaching vibrato on the violin. Thirty eight percent of the participants responded that arm vibrato was most effective, followed by $32 \%$ who taught wrist vibrato, $1 \%$ who responded finger vibrato and $29 \%$ who responded other.

I found question nine to be one of the most challenging questions to organize the data. I asked the participants to rank in order how they prioritized classroom string instruction. The concept ranked highest in importance was intonation followed by rhythm, technique, and phrasing. The results between intonation and rhythm only differed between two participant's choices. This may have been due, in part, by the limited number of respondents.

Most classroom teachers use or follow some type of method book. Question ten asked participants to list if they use a method book, which twenty-nine out of thirty one responded "yes." The next question asked participants to list the method books they use when teaching strings. Eighty six percent of participants $(N=29)$ use Essential Elements. Muller-Rusch and String Explorer were the next highest percent being used by the participants.

Question twelve asked for the participant to check the type of content they test when administering a playing exam. One hundred percent of participants $(N=31)$ test for 
rhythm and notes. Ninety-three percent checked bowings and posture, followed by tone, articulation, dynamics and then phrasing.

Responses regarding playing exams varied with how often playing exams were administered over a period of time. Five participants (36\%) gave a playing exam 2-3 times a month. Five participants (36\%) listed once a month. The participant's answers could possibly vary depending on the material being taught and the type of preparation a class might need, for example, a concert.

Question fourteen addressed the types of bowings the students use in the classroom. The majority of students use a detaché bow stroke, followed by spiccato then martelé. Some of the lesser used bow strokes were collé, and sautillé. Sixteen participants $(71 \%)$ checked "other."

Question fifteen asked for the participants to list any technique or idea that was taught to them by a former teacher. Some suggestions were to listen to a new piece before playing it, review scales, and to mentally practice. Public string teachers teach a large group of students everyday. Question sixteen asked the participants if they choose to teach private lessons in addition to their regular teaching schedules. Seventy one percent of the participants $(N=14)$ taught privately outside of the school system.

When beginning class, most teachers have a routine or some warm-up that is in place. All fourteen participants of this study begin a class with some type of warm-up routine. The last question in the survey asked for the participants to describe the routine used. Some of the activities teachers used in their class warm-up routine were stretching, 
tuning, open strings, scales, bow, rhythm and shifting exercises. These are regarded as common techniques taught frequently in a string orchestra. 


\section{SUMMARY AND CONCLUSIONS}

The purpose of this study was to identify the teaching techniques of current string teachers within the Kentucky Music Education Association. The participants included elementary, middle, and high school public string teachers in the Commonwealth of Kentucky $(N=31)$. Results collected from the survey included demographic information about the teacher, along with specific teaching techniques, for example, rehearsal warmups, scales, intonation exercises, bow exercises, rhythms and shifting.

\section{Method Books}

While conducting my research, I found a lack of research and articles in the area of string pedagogy. After completing the survey for my thesis, I have come to the conclusion that there needs to be further research done in the area of string methods and techniques being taught. Another area, similar to this study that could be explored, is the examining of methods and techniques being used in the other states in the United States. It would be interesting to compare how each region is alike or different in the resources they use in each school system. For instance, the variances in method books, at what grade level string methods are offered or how often string classes meet per week. Surprisingly, Essential Elements for Strings was the most common method book being used by string teachers. With all of the resources to choose from, I found it interesting that the majority of string teachers in the state of Kentucky use Essential Elements for Strings. Further research could investigate the reasons why this book is so widely used. 


\section{Survey}

With my actual survey, there would be some things I would consider doing differently. There were some limits of the survey when comparing the online version and the in-person handout that involved the completion of the survey. Many participants who took the survey online left some answers blank or chose not to respond. All of the inperson handouts were filled out completely. In regards to question 14 , I would have added another bow stroke, staccato, which is a fairly simple bow stroke used often in the classroom. I would have also reframed question 15 in a way to hopefully elicit more participant responses when asked to list any technique or idea that was taught to them by a former teacher.

\section{String Pedagogy}

Another idea for a future study is to create a string survey that would include string teachers registered through the American String Teacher Association (ASTA) and the Kentucky Music Education Association (KMEA). Further investigations might focus on how the string teachers supplement text books with other resources and repertoire. It would also be interesting to investigate the similarities and differences in the approach to private string teaching verses teaching in the public school. Future research could also examine if teaching outside of a classroom may possibly give a teacher a different view point on how to work with students individually on their needs to become better players. More research conducted in string education will hopefully help to better educational string programs and strengthen the teaching techniques and methods being used by string teachers. 
Lastly, it is important to examine the effectiveness of strategies being used by string teachers. Are the methods and techniques currently used reliable sources for our string educators? If not, what steps can be taken to strengthen the string curriculum? Although several string surveys have been conducted on current teaching practices across America, more research is needed (Gilliland, 2001; Schmidt, et al., 2006). 


\section{REFERENCES}

Arnold, A. J. (1995). Effects of competency-based methods of instruction and selfobservation on ensemble directors' use of sequential patterns. Journal of Research in Music Education, 43(2), 127-138.

Bergee, M. J. (1992). A scale assessing music student teachers' rehearsal effectiveness. Journal of Research in Music Education, 40(1), 5-13.

Bergonzi, L. (1997). Effects of finger markers and harmonic context on performance of beginning string students. Journal of Research in Music Education, 45(2), 197211.

Brittin, R. V. (2005). Preservice and experienced teachers' lesson plans for beginning instrumentalists. Journal of Research in Music Education, 53(1), 26-39.

Byo, J. L., \& Cassidy, J. W. (2005). The role of the string project in teacher training and community music education. Journal of Research in Music Education, 53(4), $332-347$.

Colprit, E. J. (2000). Observation and analysis of Suzuki string teaching. Journal of Research in Music Education, 48(3), 206-221.

Consortium of National Arts Education Associations. (1994). National Standards for Arts Education. Reston, VA: Music Educators National Conference.

Cowden, R. L. (1972). A comparison of first and third position approaches to violin instruction. Journal of Research in Music Education, 20(4), 505-509. 
Delzell, J. K. (1989). The effects of musical discrimination training in beginning instrumental music classes. Journal of Research in Music Education, 37(1), 2131.

Duke, R. A. \& Henniger, J.C. (2002). Teachers' verbal corrections and observers' perceptions of teaching and learning. Journal of Research in Music Education, 50 (1), 75-87.

Geringer, J. M., \& Allen, M. L. (2004). An analysis of vibrato among high school and university violin and cello students. Journal of Research in Music Education, $52(2), 167-178$.

Gholson, S. A. (1998). Proximal positioning: A strategy of practice in violin pedagogy. Journal of Research in Music Education, 46(4), 535-545.

Gillespie, R. (1991). String teachers' diagnostic skills and their students' performance competencies. Journal of Research in Music Education, 39(4), 282-289.

Gillespie, R. (1992). New possibilities: Strings are strolling! Music Educators Journal, $79(1), 23-24$.

Gillespie, R. (1997). Ratings of violin and viola vibrato performance in audio-only and audiovisual presentations. Journal of Research in Music Education, 45(2), 212220.

Gillespie, R., \& Hamann, D. L. (1998). The status of orchestra programs in the public schools. Journal of Research in Music Education, 46(1), 75-86.

Gilliland, D. (2001). A survey and comparative analysis of grading practices by public school orchestra directors in El Paso County (Doctoral dissertation). Retrieved from ProQuest Dissertations \& Theses. (EP05562) 
Gordon, D. G. (2001). Classroom management problems and solutions. Music Educators Journal, $88(2), 17-23$.

Gromko, J. E. (2005). The effect of music instruction on phonemic awareness in beginning readers. Journal of Research in Music Education, 53(3), 199-209.

Gumm, A.J. (1997). The development of a model and assessment instrument of choral music teaching styles. Journal of Research in Music Education, 41(3), 181-199.

Hale, C. L., \& Green, S. K. (2009). Six key principles for music assessment. Music Educators Journal, 95(4), 27-31.

Hallam, S. (2001). The development of expertise in young musicians: Strategy use, knowledge acquisition and individual diversity. Music Education Research, 3(1), $7-23$.

Hammel, A. M. (2004). Inclusion strategies that work. Music Educators Journal, 90(5), 33-37.

Harrison, C. S., Asmus, E. P., \& Serpe, R. T. (1994). Effects of musical aptitude, academic ability, music experience, and motivation on aural skills. Journal of Research in Music Education, 42(2), 131-144.

Hartley, L. A., \& Porter, A. M. (2009). The influence of beginning instructional grade on string student enrollment, retention, and music performance. Journal of Research in Music Education, 56(4), 370-384.

Haston, W. (2007). Teacher modeling as an effective teaching strategy. Music Educators Journal, 93(4), 26-30.

Hayes, G. R. (1926). Old ways for new in violin training. The Musical Times, 67(997), $223-224$. 
Hewitt, M. P. (2001). The effects of modeling, self-evaluation, and self-listening on junior high instrumentalists' music performance and practice attitude. Journal of Research in Music Education, 49(4), 307-322.

Hewitt, M. P. (2007). Influence of primary performance instrument and education level on music performance evaluation. Journal of Research in Music Education, 55(1), 18-30.

Jacobs, C. (1969). Investigation of kinesthetics in violin playing. Journal of Research in Music Education, 17(1), 112-114.

Kerner, E. (1969). Violin practice: Pain is pleasure's cost. Music Educators Journal, $55(8), 65-72$.

MacLeod, R. B. (2008). Influences of dynamic level and pitch register on the vibrato rates and widths of violin and viola players. Journal of Research in Music Education, 56(1), 43-54.

Madsen, K., \& Cassidy, J. W. (2005). The effect of focus of attention and teaching experience on perceptions of teaching effectiveness and student learning. Journal of Research in Music Education, 53(3), 222-233.

Morrison, S. J., Montemayor, M., \& Wilshire, E. S. (2004), The effect of a recorded model on band students performance self-evaluations, achievement, and attitude. Journal of Research in Music Education, 52(2), 116-129.

Nelson, D. J. (1984). The conservation of rhythm in Suzuki violin students: A task validation study. Journal of Research in Music Education, 32(1), 25-34.

Pedagogy. (n.d.). Online Etymology Dictionary. Retrieved April 26, 2012, from Dictionary.com website: http://dictionary.reference.com/browse/pedagogue 
Perkins, M. M. (1995). A comparison of violin playing technique: Kato Havas, Paul Rolland, and Shinichi Suzuki. Urbana, Il.: American String Teachers Association. Roberts, Chris (2011). ASTA ready to roll out national string curriculum. Strings. Retrieved from http://www.allthingsstrings.com/News/News/ASTA-Ready-toRoll-Out-National-String-Curriculum.

Rolland, P. (1947). The teaching of strings. Music Educators Journal, 33(5), 34-59.

Rosenthal, R. K. (1984). The relative effects of guided model, model only, guide only, and practice only treatments on the accuracy of advanced instrumentalists' musical performance. Journal of Research in Music Education, 32(4), 265-273.

Salzberg, R. S., \& Salzberg, C. L. (1981). Praise and corrective feedback in the remediation of incorrect left-hand positions of elementary string players. Journal of Research in Music Education, 29(2), 125-133.

Schmidt, C. P., Baker, R., Hayes, B., \& Kwan, E. (2006). A descriptive study of public school music programs in Indiana. Bulletin of the Council for Research in Music Education (169), 25-37.

Scott, L. (1992). Attention and perseverance behaviors of preschool children enrolled in Suzuki violin lessons and other activities. Journal of Research in Music Education, 40(3), 225-235.

Smith, C. M. (1995). Development of performance pitch accuracy of string students. Bulletin of the Council for Research in Music Education (124), 13-23.

Smith, C. M. (1997). Access to string instruction in American public schools. Journal of Research in Music Education, 45(4), 650-662. 
Stuart, M. (1979). The use of videotape recordings to increase teacher trainees' error detection skills. Journal of Research in Music Education, 27(1), 14-19.

Wagner, M. J., \& Strul, E. P. (1979). Comparisons of beginning versus experienced elementary music educators in the use of teaching time. Journal of Research in Music Education, 27(2), 113-125.

Witt, A.C. (1986). Use of class time and student attentiveness in secondary instrumental music rehearsals. Journal of Research in Music Education, 34(1), 34-42. 


\section{APPENDIX \\ String Teaching Techniques Survey}

Please type Yes to confirm your consent of the use of your responses to the following questions included in this survey.

What grade level/levels and classes do you currently teach?

How many years of experience do you have teaching a school string program?

Please list the total amount of teaching time you spend with each of your orchestra or string classes per week. (Example: High school orchestra- 4 hours).

What is your primary instrument?

Do you teach vibrato?

O Yes

No 
What developmental stage do you think students should first be introduced to vibrato?
O 1 year
O 2 year
O 3 year
O 4 year
O 5 year
O Other

What do you think is the most effective method in teaching vibrato on the violin?
Arm Vibrato
Wrist Vibrato
O Finger Vibrato
Other

Rank in order 1-4, with 1 being most important and 4 being least important for how you prioritize classroom string instruction.

Technique/ Articulation

\begin{tabular}{ll}
\hline & Phrasing \\
& Rhythm \\
& Intonation
\end{tabular}

Do you use a method book(s) in your rehearsals?

$\begin{array}{ll}O & \text { Yes } \\ O & \text { No }\end{array}$

If so, please list the title(s). 
Check the type of content you test when administering a playing exam to students. If you do not give playing exams please skip the question.

\begin{tabular}{|c|c|c|c|c|c|c|c|c|c|}
\hline & Rhythm & Notes & Phrasing & Bowings & Posture & Articulation & Tone & Dynamics & Other \\
\hline $\begin{array}{c}\text { Please } \\
\text { check }\end{array}$ & $\square$ & $\square$ & $\square$ & $\square$ & $\square$ & $\square$ & $\square$ & $\square$ & $\square$ \\
\hline
\end{tabular}

Please specify how often playing exams are administered.

O Never

O Less than Once a Month

Once a Month

O 2-3 Times a Month

O Once a Week

O 2-3 Times a Week

Daily

Select the bowings you use during class instruction.

De'tache'

a Martele'

a Colle'

口 Sautille'

Spiccato

$\square$ Other

If any, list a technique or idea that you find most effective that was taught to you by a former teacher.

Do you teach private or individual lessons outside of the school system?

O Yes

No 
Do you begin your class with a warm-up?

Yes

O No

If you answered yes to the following question, describe your warm-up routine at the beginning of a rehearsal. 
THE KMEA AND ITS STRING PROGRAM:

TEACHING TECHNIQUES OF STRING TEACHERS

Date December 2011

Dear Participant,

You are being invited to participate in a research study by answering the attached survey about string methods and techniques being used in the classrooms in the state of Kentucky. There are no known risks for your participation in this research study. The information collected may not benefit you directly. The information learned in this study may be helpful to others. The information you provide will be data for string current and future string teachers. Your completed survey will be stored at the University of Louisville. The survey will take approximately 5 minutes time to complete.

Individuals from the Department of Music Education, the Institutional Review Board (IRB), the Human Subjects Protection Program Office (HSPPO), and other regulatory agencies may inspect these records. In all other respects, however, the data will be held in confidence to the extent permitted by law. Should the data be published, your identity will not be disclosed.

Taking part in this study is voluntary. By completing this survey you agree to take part in this research study. You do not have to answer any questions that make you uncomfortable. You may choose not to take part at all. If you decide to be in this study you may stop taking part at any time. If you decide not to be in this study or if you stop taking part at any time, you will not lose any benefits for which you may qualify.

If you have any questions, concerns, or complaints about the research study, please contact: L. Blair Joseph 270-703-1312. 
If you have any questions about your rights as a research subject, you may call the Human Subjects Protection Program Office at (502) 852-5188. You can discuss any questions about your rights as a research subject, in private, with a member of the Institutional Review Board (IRB). You may also call this number if you have other questions about the research, and you cannot reach the research staff, or want to talk to someone else. The IRB is an independent committee made up of people from the University community, staff of the institutions, as well as people from the community not connected with these institutions. The IRB has reviewed this research study.

If you have concerns or complaints about the research or research staff and you do not wish to give your name, you may call 1-877-852-1167. This is a 24 hour hot line answered by people who do not work at the University of Louisville.

Sincerely,

Blair Joseph

Dr. Amy Acklin 


\section{CURRICULUM VITAE}

\section{Blair Joseph}

1800 S. 2nd St. Apt. 23 * Louisville, KY. 40208

DO I3: Kentucky - July 28, 1984

\section{EDICATION}

Murray State University, Murray, KY

Degree: Bachelor of Arts

Major: Music

Minor: Journalism and Mass Communications

Graduation Date:

May 2007

University of Louisville, Louisville, KY

Degree: Master of Music Education

Expected Graduation Date: May 2012

EXPERIENCE

Orchestra Director

October 2012

Southern High School

T.T. Knight Middle School

Blue Lick and Laukhuf Elementary 